\title{
Identification of Botryosphaeriaceae Species Causing Kiwifruit Rot in Sichuan Province, China
}

You Zhou and Guoshu Gong, Department of Plant Pathology, College of Agriculture, Sichuan Agricultural University, Chengdu 611130, P. R. China; Yongliang Cui, Department of Plant Pathology, College of Agriculture, Sichuan Agricultural University, and Sichuan Academy of Natural Resource and Sciences, Chengdu 610041, P. R. China; Daixi Zhang, College of Veterinary Medicine, Sichuan Agricultural University, Chengdu 611130, P. R. China; Xiaoli Chang, Department of Plant Pathology, College of Agriculture, Sichuan Agricultural University; Rongping Hu, Sichuan Academy of Agricultural Sciences, Chengdu 611130, P. R. China; and Na Liu and Xiaofang Sun, Department of Plant Pathology, College of Agriculture, Sichuan Agricultural University

\begin{abstract}
Zhou, Y., Gong, G., Cui, Y., Zhang, D., Chang, X., Hu, R., Liu, N., and Sun, X. 2015. Identification of Botryosphaeriaceae species causing kiwifruit rot in Sichuan Province, China. Plant Dis. 99:699-708.

Species of Botryosphaeriaceae fungi are important plant pathogens causing cankers, blight, and fruit rot in an extremely wide range of host. In recent years, kiwifruit rot has been a serious problem in Sichuan Province, one of the important kiwifruit production areas of China. Botryosphaeria dothidea has previously been associated with kiwifruit rot but little is known regarding whether other Botryosphaeriaceae genera also constitute kiwifruit rot pathogens in China. Accordingly, diseased fruit were collected from six different areas of Sichuan Province. Based on morphological characteristics, pathogenicity testing, and comparisons of DNA sequences of the internal transcribed spacer, transcription elongation factor $1-\alpha$, and $\beta$-tubulin genes, 135 isolates of Botryosphaeriaceae were identified as B. dothidea, Lasiodiplodia theobromae, and Neofusicoccum parvum. All of these species were found to cause kiwifruit rot. To understand the infection

cycle of kiwifruit rot pathogens, these three species were used to inoculate leaves and shoots of kiwifruit. The results showed that these species could cause spots on leaves and lesions on shoots, producing abundant pycnidia on leaves and shoots surfaces. Moreover, B. dothidea conidia and ascospores from overwintered pycnidia and pseudothecia in kiwifruit orchards in April and August could cause fruit rot and spots on leaves of kiwifruit. Therefore, we concluded that overwintered pycnidia and pseudothecia of $B$. dothidea in kiwifruit orchards are the primary inoculum for kiwifruit rot, with new pycnidia that develop during the growing season serving as a secondary inoculum. This is the first report of N. parvum and L. theobromae causing kiwifruit rot in China and is also the first report that $B$. dothidea is able to overwinter as pycnidia and pseudothecia in kiwifruit orchards and serve as the primary inoculum for kiwifruit rot.
\end{abstract}

Sichuan Province is a main kiwifruit (Actinidia chinensis Planch.) growing area in China, with an annual production of approximately 84 million $\mathrm{kg}$ (58). 'Hongyang' is the first red-flesh cultivar developed from A. chinensis var. rufopulpa and is also the most popular cultivar. However, postharvest kiwifruit rot has caused serious fruit losses in Sichuan in recent years. Our survey from 2010 to 2013 indicated that kiwifruit rot frequently occurs during storage and sometimes before harvest (unpublished observation). Because Botryosphaeriaceae species are frequently isolated from rotten fruit, we regard fungi in the Botryosphaeriaceae family as potentially the major causal organisms of postharvest kiwifruit rot in Sichuan.

The symptoms of kiwifruit rot begin as small brown spots. The spots enlarge rapidly and develop a clear, hydrotic ring surrounded by a dark-green margin; diseased fruit then develop a watery soft rot. White mycelia emerge from infected fruit epidermal tissues, and the broken skin allows fluid to exude from severely decayed fruit. Several fungal genera have been reported in association with kiwifruit rot, including species of Alternaria, Botryosphaeria, Botrytis, Colletotrichum, Cryptosporiopsis, Cylindrocarpon, Diaporthe (anamorph: Phomopsis), Mucor, Penicillium, Phoma, and Sclerotinia $(12,16,20,22,26,28)$. However, not all of these fungi are equally important as causal agents of kiwifruit rot. Botryosphaeria and Phomopsis spp. were reported as being most closely associated with postharvest kiwifruit rot (16). Phomopsis spp. were found to cause kiwifruit rot during ripening but could not readily infect unwounded fruit (20).

Corresponding author: G. Gong; E-mail: guoshugong@126.com

Accepted for publication 23 January 2015.

http://dx.doi.org/10.1094/PDIS-07-14-0727-RE

(C) 2015 The American Phytopathological Society
It is widely known that most Botryosphaeria spp. are wound pathogens. However, research has revealed that Botryosphaeria dothidea can infect unwounded leaves of eucalyptus and unwounded fruit of apple, olive, and pistachio $(13,19,24,25,41)$ through lenticels, surface cracks, and stomata. Botryosphaeria is the most important and common fungal genus causing cankers, blight, and fruit rot, with an extremely wide host range that includes apple, eucalyptus, grape, kiwifruit, olive, and peach across a broad geographical distribution $(2,16,35,46,48)$. The genus Botryosphaeria was established by Cesati and De Notaris in 1863, and the type species is Botryosphaeria dothidea (Moug.) Ces. \& De Not (6). The position of genus Botryosphaeria has undergone a considerable amount of revision since Lindau assigned it to the family Melogrammataceae in 1897 (7). In 1915, Theissen and Sydow created the subfamily Botryosphaerieae and placed genus Botryosphaeria in it (49). Three years later, the family Botryosphaeriaceae was introduced by Theissen and Sydow and included genus Botryosphaeria (50). In 1923, Petrak placed genus Botryosphaeria in family Pseudosphaerieae (30). However, after several changes, genus Botryosphaeria was retained in family Botryosphaeriaceae in the order Dothideales (54). This classification is widely accepted by mycologists $(6,7,15)$.

The Botryosphaeria teleomorph is rarely observed in culture, whereas anamorphs are common (53). Thus, the morphological classification and identification of Botryosphaeria spp. are mainly based on the features of its anamorph stage (40). Anamorphs of Botryosphaeria traditionally including 18 genera. However, Denman et al. revised the previous studies and accepted two anamorphs of Botryosphaeria (Diplodia-like and Fusicoccum-like), mainly based on morphological characteristics and phylogenetic analyses of internal transcribed spacer (ITS) sequences in 2000 (7). In 2006, Crous et al. revised the previous studies of genus Botryosphaeria according to morphological characteristics and 28S ribosomal DNA sequences, and redefined Botryosphaeria with a Fusicoccum anamorph (6). Therefore, genus Botryosphaeria was considered to retain $B$. dothidea and $B$. corticis $(1,33,34,47)$. The remaining species, which were previously known as Botryosphaeria 
(such as Diplodia, Dothiorella, Lasiodiplodia, Neofusicoccum, Neoscytalidium, Macrophomina, and Pseudofusicoccum spp.) were moved into the Botryosphaeriaceae family $(1,6,47)$. In 2013, Phillips et al. accepted seven Botryosphaeria spp. (B. agaves, B. corticis, B. dothidea, B. fabicerciana, B. fusispora, B. ramosa, and B. scharifii) based largely on morphological characteristics and sequence analyses of five nuclear loci (ITS, $\beta$-tubulin [BT], transcription elongation factor $1-\alpha$ [TEF], large subunit nuclear ribosomal DNA [LSU], and small subunit nuclear ribosomal DNA [SSU]) (32). Among these Botryosphaeria spp., $B$. dothidea has been reported to cause kiwifruit rot in China, Japan, Korea, and New Zealand $(14,16,18)$. In addition to $B$. dothidea, three Botryosphaeriaceae species—Diplodia mutila (syn. B. stevensii), Neofusicoccum luteum (syn. Botryosphaeria lutea) and N. parvum (syn. B. parva) - have been isolated from rotten fruit but their pathogenicity has not been verified $(12,22)$. In addition to kiwifruit rot, $B$. dothidea and N. parvum were reported to cause shoot blight of kiwifruit in Greece $(37,51)$. In a recent family concept of the Botryosphaeriaceae, Phillips et al. accepted 17 genera into the family (32). Although the characteristics of anamorphs are very important for identification of species of Botryosphaeriaceae, some of these characteristics are overlapping and variable (8). Thus, identification of Botryosphaeriaceae species is based mainly on morphological characteristics combined with molecular data. Indeed, molecular data play an important role in current mycological taxonomy, wherein the ITS, BT, and TEF genes are the most powerful and reliable for accurate identification $(21,23,27,29)$

To our knowledge, there has been no investigation of Botryosphaeriaceae species causing kiwifruit rot in China. Thus, the objectives of this study were to (i) identify species of Botryosphaeriaceae causing kiwifruit rot based on morphological and phylogenetic analyses and pathogenicity tests and (ii) determine the primary inoculum sources of pathogens in the Botryosphaeriaceae family causing kiwifruit rot in Sichuan Province, China.

\section{Materials and Methods}

Isolates from rotten fruit and morphological characterization. From 2010 to 2013, rotten fruit of Hongyang kiwifruit were collected from commercial kiwifruit orchards and fruit storage facilities during the kiwifruit harvesting seasons in the Cangxi, Dujiangyan, Mingshan, Pengzhou, Qionglai, and Shuangliu regions of Sichuan Province. The diseased fruit were rinsed in running tap water and air dried on a sterile bench top. The margin between symptomatic and apparently healthy tissues was cut into small pieces ( 4 by $4 \mathrm{~mm}$ ). These pieces were surface sterilized in $70 \%$ ( $\mathrm{vol} / \mathrm{vol}$ ) ethanol for approximately $20 \mathrm{~s}$ and then rinsed in $1 \%$ (wt/vol) $\mathrm{NaOCl}$ for $40 \mathrm{~s}$, followed by rinsing three times with sterilized distilled water. Finally, moisture was removed by blotting with sterilized filter paper, and the pieces were placed on potato dextrose agar (PDA) containing streptomycin $(50 \mu \mathrm{g} / \mathrm{ml})$. The plates were incubated in the dark at $25^{\circ} \mathrm{C}$. All fast-growing fungal colonies characteristic of the Botryosphaeriaceae family (fluffy white to graygreen in color) were subcultured on PDA plates by excising hyphal tips from the colony margins. Pure cultures were transferred to PDA slants and stored in a refrigerator at $4^{\circ} \mathrm{C}$ until use.

The cultural characteristics of the isolates were recorded on PDA at $25^{\circ} \mathrm{C}$. For inducing sporulation, the isolates were cultured on PDA at $25^{\circ} \mathrm{C}$ under near-UV light with $12 \mathrm{~h}$ of an intermittent cycle per day until conidia were produced in pycnidia ( 4 to 7 weeks). The conidial color and shape were noted, and the length and width of 80 conidia per isolate were measured using a compound microscope (ECLIPSE 80i; Nikon, Japan). Botryosphaeriaceae isolates were tentatively identified based on a comparison with morphological characteristics of colonies and conidia reported in previous taxonomic studies $(17,31,32,38)$.

DNA extraction, sequence amplification, and phylogenetic analysis. Total DNA was extracted from pure cultures using the method described by Barnes et al. (3). The polymerase chain reaction mixtures (PCR; $50 \mu \mathrm{l}$ ) contained $1 \mu \mathrm{l}$ of genomic DNA (approximately $100 \mathrm{ng}$ ), $1 \mu l$ of each primer $(10 \mathrm{mM}), 22 \mu l$ of sterile deionized water, $25 \mu l$ of $2 \times$ Taq PCR Mastermix (Taq DNA polymerase at $0.05 \mathrm{U} / \mu \mathrm{l}, 4 \mathrm{mM}$ $\mathrm{MgCl}_{2}$, and 0.4 mM dNTPs; Sangon Biotech Co., Ltd., Shanghai, China). The ITS region was amplified using the ITS1 and ITS4 primers (57), and the PCR cycling parameters were $94^{\circ} \mathrm{C}$ for $3 \mathrm{~min}$; followed by 35 cycles of $94^{\circ} \mathrm{C}$ for $45 \mathrm{~s}, 58^{\circ} \mathrm{C}$ for $45 \mathrm{~s}$, and $72^{\circ} \mathrm{C}$ for $1 \mathrm{~min}$; with a final extension step at $72^{\circ} \mathrm{C}$ for $10 \mathrm{~min}$. The primer pair EF1-728F and EF1-986R was used to amplify a segment of the TEF gene (55). The amplification conditions were denaturation at $95^{\circ} \mathrm{C}$ for $3 \mathrm{~min}$; followed by 35 cycles of $25 \mathrm{~s}$ at $95^{\circ} \mathrm{C}, 30 \mathrm{~s}$ at $58^{\circ} \mathrm{C}$, and $40 \mathrm{~s}$ at $72^{\circ} \mathrm{C}$; and a final extension period of $10 \mathrm{~min}$ at $72^{\circ} \mathrm{C}$. The partial BT gene was amplified using the primers Bt2a and Bt $2 \mathrm{~b}(33)$ and the cycling parameters were $95^{\circ} \mathrm{C}$ for $3 \mathrm{~min}$; followed by 34 cycles of $95^{\circ} \mathrm{C}$ for $1 \mathrm{~min}, 52^{\circ} \mathrm{C}$ for $30 \mathrm{~s}$, and $72{ }^{\circ} \mathrm{C}$ for $1 \mathrm{~min}$; and a final extension step at $72^{\circ} \mathrm{C}$ for $10 \mathrm{~min}$. The PCR products were sequenced by Sangon Biotech Co., Ltd. using an ABI-PRISM3730 automated sequencer (Applied Biosystems, Foster City, CA). Reference nucleotide sequences of ITS, TEF, and BT were obtained from GenBank according to previous publications $(1,4,32,39)$. All sequences were aligned with ClustalX 1.7 (56), and characteristics were weighted equally. Maximum-parsimony trees were based on the close-neighbor-interchange algorithm of MEGA5 with 1,000 bootstrap replicates, and gaps were excluded $(5,44,45)$. The tree length (TL), consistency index (CI), retention index (RI), and rescaled consistency index (RCI) were also calculated.

Pathogenicity tests of isolates from rotten fruit. Preparation of Botryosphaeriaceae inocula. The method described by Guo et al. was used to obtain conidia for pathogenicity tests on fruit, leaves, and shoots of kiwifruit (10). Healthy kiwifruit shoots were cut into approximately 7 -cm segments, placed in $200-\mathrm{ml}$ flasks, and autoclaved at $121^{\circ} \mathrm{C}$ for $30 \mathrm{~min}$. Ten plugs ( $5 \mathrm{~mm}$ in diameter) of each Botryosphaeriaceae isolate were removed from 6-day-old cultures on PDA and transferred to flasks containing the sterilized shoots, with one flask per isolate. The inoculated shoots were cultured at $25^{\circ} \mathrm{C}$ in a cycle of $12 \mathrm{~h}$ of near-UV light and $12 \mathrm{~h}$ of darkness per day until pycnidia appeared. The flasks were shaken once every 5 days to keep the shoots from clustering. Mature pycnidia of each isolate were collected from colonized shoots and crushed in sterile distilled water. The resulting conidial suspensions were filtered through sterile, four-layer cotton gauze to remove mycelia and unwanted pycnidial debris (46), then diluted to $10^{4}$ conidia $\mathrm{ml}^{-1}$. The conidial suspensions $\left(10^{4}\right.$ conidia $\left.\mathrm{ml}^{-1}\right)$ and 5-mm-diameter mycelial plugs from 6-day-old PDA cultures of each isolate were used as the inocula for pathogenicity tests on fruit, leaves, and shoots, as described below.

Pathogenicity of isolates on fruit and leaves of kiwifruit. Healthy and near-ripe Hongyang fruit were surface-disinfested with $1 \%(\mathrm{wt} / \mathrm{vol})$ $\mathrm{NaOCl}$ for approximately $1 \mathrm{~min}$, followed by washing with sterilized water, then air dried on a sterile bench top. One inoculation was performed in the side of each fruit. Healthy detached kiwifruit leaves were surface disinfested with $70 \%$ (vol/vol) ethanol for approximately $15 \mathrm{~s}$, washed with sterilized water, and air dried on a sterile bench top. Two or four inoculations were performed on each leaf surface.

The pathogenicity tests included wounded and unwounded plant material. Thirteen isolates from rotten fruit were used to inoculate fruit and leaves (Table 1). For wounded inoculations, 20- $\mu$ l conidial suspensions or a mycelial plug were directly placed on wounded fruit and leaves, respectively, which were injured with a sterilized pointed needle. For unwounded inoculations, a $20-\mu l$ conidial suspension or mycelial plug was placed on intact fruit and leaves, respectively. For the uninoculated controls, $20-\mu \mathrm{l}$ of sterile distilled water and 5-mmdiameter plugs of PDA only were used to inoculate wounded and unwounded controls, respectively.

Fruit of two other kiwifruit cultivars ('Hort' and 'Miliang'), apple (Malus domestica Borkh 'Fuji'), and pear (Pyrus pyrifolia Nakai 'Huangjin') were used to test the pathogenicity of three different morphotype isolates: Mht-5, Mht-17, and Mht-18. Mycelial plugs of these three isolates were placed on wounds made by a dissecting needle. Plugs of PDA only were used as controls.

For all inoculation treatments, three fruit or leaves were used as a replicate, and three replicates were used for each treatment and control. The inoculated fruit were kept in sterilized, transparent plastic boxes under a cycle of $12 \mathrm{~h}$ of darkness and $12 \mathrm{~h}$ of light at $25^{\circ} \mathrm{C}$. The inoculated leaves were placed on sterilized, moistened tissue paper in sterilized boxes under the same conditions as the fruit. The presence or absence of disease symptoms was determined 2 days after inoculation. All experiments were repeated twice. 
Pathogenicity on wounded shoots of kiwifruit. Two types of wounded shoots were used to test the pathogenicity of isolates Mht-4, Mht-5, Mht-17, Mht-18, Mht-37, Mht-44, and Mht-55 (Table 1). Healthy 1-year-old shoots were cut into 8-cm lengths and surface sterilized with $70 \%$ (vol/vol) ethanol. For the first experiment, a $60-\mu \mathrm{l} \mathrm{co-}$ nidial suspension or mycelial plug was applied to a rounded wound ( $5 \mathrm{~mm}$ in diameter and $4 \mathrm{~mm}$ in depth) of shoot made using a sterile cork borer. In the second experiment, a wound was made in the middle of the shoot with a sterilized pointed needle, and a $20-\mu l$ conidial suspension or mycelial plug was placed in the wound. The two types of wounded shoots were inoculated with 60 or $20 \mu \mathrm{l}$ of sterile distilled water or nonfungal PDA plugs as controls. All inoculated sites were wrapped with Parafilm sterilized by ultraviolet light. Three shoots were used as a replicate, and three replicates were used for each treatment and control. For moistening purpose, all shoots were placed on sterile wet tissue paper. Shoot tests were conducted in sterilized, transparent plastic boxes under a cycle of $12 \mathrm{~h}$ of darkness and $12 \mathrm{~h}$ of light at $25^{\circ} \mathrm{C}$. Disease was evaluated after 7 days. Each experiment was repeated twice.

In addition, twigs and 1-year-old shoots attached to kiwifruit trees were used to test the pathogenicity of isolate Mht-5 in a kiwifruit orchard in the city Dujiangyan, Sichuan Province. The inoculation sites on twigs and shoots were surface disinfested with $70 \%$ (vol/vol) ethanol, rinsed with sterile water, and allowed to dry naturally. The twigs and shoots were then wounded with a sterilized pointed needle. A mycelial plug of Mht-5 was placed in each wound, wrapped in Parafilm, and then covered with petroleum jelly. Nonfungal PDA plugs were used as controls. Each treatment had three replicates, with three twigs or shoots per replicate. Disease symptoms were evaluated after 10 days. Each experiment was repeated twice.

The pathogenicity of overwintered conidia and ascospores. To test the hypothesis that overwintered pycnidia and pseudothecia of
Botryosphaeriaceae species in kiwifruit orchards can serve as the primary inoculum for kiwifruit rot, wood was collected from kiwifruit trees after fruit was harvested in September 2011. The material was then placed in an open area of kiwifruit orchards. In April and August 2012, wood with abundant fruiting bodies was selected, and the morphology of the fruiting bodies was characterized under a dissecting microscope (SZX16; Olympus, Japan). Pycnidia and pseudothecia were placed on a microscope slide and crushed in sterile distilled water. The conidia and ascospores were identified by their morphological characteristics under a compound microscope (ECLIPSE 80i; Nikon). Conidia that appeared similar were collected in $25 \mathrm{ml}$ of sterile water in a 50-ml tube. Similarly, the same species of ascospores were collected in sterile tubes. The tubes were shaken until the conidia and ascospores were released into the water. The spore suspension was filtered through sterile gauze to remove debris.

To verify the morphological identifications, six conidia were selected from a conidial suspension of each Botryosphaeriaceae species and single-spore cultured; six ascospores from an ascospore suspension of each Botryosphaeriaceae species were also single-spore cultured. For molecular identification, genomic DNA was extracted from four representative single-spore cultured isolates (Mht-19, Mht-32, Mht76, and Mht-88). Among the four isolates, Mht-19 and Mht-76 were obtained from conidial suspensions in April and August 2012, respectively. The isolates Mht-32 and Mht- 88 were obtained from ascospore suspensions in April and August 2012, respectively (Table 1).

To determine the pathogenicity of conidia and ascospores on fruit and leaves of kiwifruit, the collected conidial and ascospore suspensions were diluted to $10^{4}$ conidia or ascospores $\mathrm{ml}^{-1}$. The two types of inocula were used to inoculate fruit and leaves (wounded and unwounded) (Table 1), and the procedures were the same as the inoculation approaches (mentioned above) used for the conidial

Table 1. Isolates of Botryosphaeria dothidea, Lasiodiplodia theobromae, and Neofusicoccum parvum isolated from kiwifruit; their origin, symptoms produced on fruit, leaves, and shoots; and National Center for Biotechnology Information (NCBI) accession codes of internal transcribed spacer (ITS), transcription elongation factor $1-\alpha$ (TEF), and $\beta$-tubulin (BT) genes sequences

\begin{tabular}{|c|c|c|c|c|c|c|c|c|c|c|c|c|c|c|}
\hline \multirow[b]{3}{*}{ Isolates $^{\mathbf{b}}$} & & & \multicolumn{9}{|c|}{ Symptoms $^{\mathrm{a}}$} & & & \\
\hline & \multicolumn{2}{|c|}{ Origin } & \multicolumn{3}{|c|}{ Fruit } & \multicolumn{3}{|c|}{ Leaves } & \multicolumn{3}{|c|}{ Shoots } & \multicolumn{3}{|c|}{ NCBI accession code } \\
\hline & Region $^{c}$ & Part & Conidia & MP & $\overline{\mathrm{AS}}$ & Conidia & MP & $\overline{\mathrm{AS}}$ & Conidia & MP & $\overline{\mathrm{AS}}$ & ITS & TEF & BT \\
\hline \multicolumn{15}{|l|}{ B. dothidea } \\
\hline Mht-9 & SL & Fruit & $+\oplus$ & $+\oplus$ & NT & $+\oplus$ & $+\oplus$ & NT & NT & NT & NT & KJ381062 & $\ldots$ & $\ldots$ \\
\hline Mht-18 & QL & Fruit & $+\oplus$ & $+\oplus$ & NT & $+\oplus$ & $+\oplus$ & NT & $+\odot$ & $+\odot$ & NT & JN662929 & JN662927 & JX392807 \\
\hline Mht-28 & MS & Fruit & $+\oplus$ & $+\oplus$ & NT & $+\oplus$ & $+\oplus$ & NT & NT & NT & NT & KJ381064 & $\ldots$ & $\ldots$ \\
\hline Mht-37 & DJY & Fruit & $+\oplus$ & $+\oplus$ & NT & $+\oplus$ & $+\oplus$ & NT & $+\odot$ & $+\odot$ & NT & KJ381066 & $\ldots$ & $\ldots$ \\
\hline Mht-44 & $\mathrm{CX}$ & Fruit & $+\oplus$ & $+\oplus$ & NT & $+\oplus$ & $+\oplus$ & NT & $+\odot$ & $+\odot$ & NT & KJ381067 & $\ldots$ & $\ldots$ \\
\hline Mht-47 & $\mathrm{PZ}$ & Fruit & $+\oplus$ & $+\oplus$ & NT & $+\oplus$ & $+\oplus$ & NT & NT & NT & NT & KJ381068 & $\ldots$ & $\ldots$ \\
\hline Mht-19 & DJY & Shoot & $+\oplus$ & $+\oplus$ & NT & $+\oplus$ & $+\oplus$ & NT & NT & NT & NT & KC864746 & KC864748 & KC864747 \\
\hline Mht-32 & DJY & Shoot & $+\oplus$ & $+\oplus$ & NT & $+\oplus$ & $+\oplus$ & NT & NT & NT & NT & KJ381065 & $\ldots$ & $\ldots$ \\
\hline Mht-76 & DJY & Shoot & $+\oplus$ & $+\oplus$ & NT & $+\oplus$ & $+\oplus$ & NT & NT & NT & NT & KJ381063 & $\ldots$ & $\ldots$ \\
\hline Mht- 88 & DJY & Shoot & $+\oplus$ & $+\oplus$ & NT & $+\oplus$ & $+\oplus$ & NT & NT & NT & NT & KJ801792 & KJ801794 & KJ801793 \\
\hline AS1 & DJY & Shoot & NT & NT & NT & NT & NT & $+\oplus$ & NT & NT & NT & $\ldots$ & $\ldots$ & $\ldots$ \\
\hline $\mathrm{CO} 1$ & DJY & Shoot & NT & NT & NT & $+\oplus$ & NT & NT & NT & NT & NT & $\ldots$ & $\ldots$ & $\ldots$ \\
\hline AS2 & DJY & Shoot & NT & NT & $+\oplus$ & NT & NT & $+\oplus$ & NT & NT & NT & $\ldots$ & $\ldots$ & $\ldots$ \\
\hline $\mathrm{CO} 2$ & DJY & Shoot & $+\oplus$ & NT & NT & $+\oplus$ & NT & NT & NT & NT & NT & $\ldots$ & $\ldots$ & $\ldots$ \\
\hline \multicolumn{15}{|c|}{ L. theobromae } \\
\hline Mht-4 & DJY & Fruit & $+\oplus$ & $+\oplus$ & NT & $+\oplus$ & $+\oplus$ & NT & $+\odot$ & $+\odot$ & NT & KJ381073 & $\ldots$ & $\ldots$ \\
\hline Mht-5 & DJY & Fruit & $+\oplus$ & $+\oplus$ & NT & $+\oplus$ & $+\oplus$ & NT & $+\odot$ & $+\odot$ & NT & JQ658976 & JQ658977 & JQ658978 \\
\hline \multicolumn{15}{|l|}{ N. parvum } \\
\hline Mht-17 & DJY & Fruit & $+\oplus$ & $+\oplus$ & NT & $+\oplus$ & $+\oplus$ & NT & $+\odot$ & $+\odot$ & NT & JN662928 & JN662926 & JX392806 \\
\hline Mht-61 & MS & Fruit & $+\oplus$ & $+\oplus$ & NT & $+\oplus$ & $+\oplus$ & NT & NT & NT & NT & KJ381069 & $\ldots$ & $\ldots$ \\
\hline Mht-53 & QL & Fruit & $+\oplus$ & $+\oplus$ & NT & $+\oplus$ & $+\oplus$ & NT & NT & NT & NT & KJ381070 & $\ldots$ & $\ldots$ \\
\hline Mht-55 & $\mathrm{CX}$ & Fruit & $+\oplus$ & $+\oplus$ & NT & $+\oplus$ & $+\oplus$ & NT & $+\odot$ & $+\odot$ & NT & KJ381071 & $\ldots$ & $\ldots$ \\
\hline Mht-60 & $\mathrm{PZ}$ & Fruit & $+\oplus$ & $+\oplus$ & NT & $+\oplus$ & $+\oplus$ & NT & NT & NT & NT & KJ381072 & $\ldots$ & $\ldots$ \\
\hline
\end{tabular}

${ }^{a}$ Symbols: MP = mycelial plug and AS = ascospores; + = the fungal infected needle-pricked wounded fruit, leaves, and shoots of kiwifruit, showing symptoms; $\oplus=$ the fungal infected unwounded fruit and leaves of kiwifruit, showing symptoms; $\odot=$ the fungal infected the shoots with wound made with a cork borer, showing symptoms; and NT = not tested.

b Symbols: AS1 = ascospores obtained in April 2012; CO1 = conidia obtained in April 2012; AS2 = ascospores obtained in the August of 2012; and CO2 = conidia obtained in August 2012.

c Symbols: CX, DJY, MS, PZ, QL, and SL indicate the Cangxi, Dujiangyan, Mingshan, Pengzhou, Qionglai, and Shuangliu regions of Sichuan Province, respectively. 
suspensions of isolates from rotten fruit. Three fruit or leaves were used as a replicate, and each treatment and control was repeated three times. The entire experiment was repeated twice.

In addition, conidial and mycelial plugs of isolates Mht-19, Mht32, Mht-76, and Mht-88 were also used for pathogenicity tests on fruit and leaves (wounded and wounded) (Table 1). The inocula preparation and inoculation approaches (mentioned above) of these isolates were the same as the methods for the Botryosphaeriaceae isolates from rotten fruit. Each treatment and control contained three replicates, and every replicate included three fruit or leaves. The entire experiment was repeated twice.

\section{Results}

Isolates and morphological characterization. In total, 135 isolates of species in the Botryosphaeriaceae family were obtained from rotten fruit from the kiwifruit orchards and storage facilities of six regions in Sichuan Province. All isolates were grouped into three different morphotypes. According to morphological and molecular characteristics, the three morphotype isolates were identified as $B$. dothidea, Lasiodiplodia theobromae, and $N$. parvum. The relative abundance of B. dothidea, L. theobromae, and N. parvum was 62.96, 2.22 , and $34.81 \%$, respectively.

Taxonomy. Botryosphaeria dothidea (Moug.:Fr.) Ces. \& De Not., Comm. Soc. Crittog. Ital. 1 (4):212. 1863 (Fig. 1A-D.

The colony color was initially gray, turning black and fluffy after approximately 5 to 7 days. Pycnidia were produced on PDA after approximately 15 days, dark gray to black, initially covered with olivaceous dense mycelium, erumpent when mature, solitary or aggregated in small groups, unilocular or multilocular, ostioles round or irregular and well-defined. Conidiogenous cells hyaline, subcylindrical. Conidia thin-walled, 18.9-30.1 $\times$ 4.3-8.0 $\mu \mathrm{m}$ (average $=$ $25.3 \times 5.6 \mu \mathrm{m}, n=80$ ), L/W 3.1 to 5.8 (average $=4.6, n=80$ ), narrowly fusiform to subclavate, apex subobtuse, base truncate to bluntly rounded, at first hyaline, unicellular, finally pale brown and rarely 1-septum. Pseudothecia black (obtained from kiwifruit dead wood in orchards), erumpent, subglobose, up to $550 \mu \mathrm{m}$ in diameter, rarely solitary and often clustered, short papillae with suborbicular ostiole. Asci bitunicate, clavate and sometimes curved, 65.47 to $132.46 \times 13.09$ to $21.38 \mu \mathrm{m}$ (average $=92.19 \times 16.06 \mu \mathrm{m}, n=80$ ), 8 -spored, apex rounded, apical chamber present, stalked. Ascospores hyaline, one cell, fusoid to ovoid, biseriate and partially overlapping in asci, 15.53 to $29.60 \times 6.31$ to $10.82 \mu \mathrm{m}$ (average $=21.74 \times$ $8.13 \mu \mathrm{m}, n=80$ ), L/W 1.89 to 2.96 (average $=2.45, n=80$ ).

Lasiodiplodia theobromae (Pat.) Griffon \& Maubl., Bull. trimest. Soc. Mycol. Fr. 25:57. 1909 (Fig. 1 E-H).

The colony was grayish, and aerial mycelia were very rich at the beginning phase, later turning black with aging. Pycnidia were produced on PDA after approximately 12 days, unilocular or multilocular, more or less globose, dark brown to black, erumpent, solitary, papillate, ostiole central and circular. Paraphyses hyaline, septate, up to $62 \mu \mathrm{m}$ long and $4 \mu \mathrm{m}$ wide, ends rounded. Conidia developed on conidiogenous cells that were between paraphyses. Conidia subovoid to ellipsoid, broadly rounded at the apex and base, hyaline and unicellular when immature, finally dark brown with 1-septum in the middle, 21.8 to $30.4 \times 10.28$ to $14.9 \mu \mathrm{m}$ (average $=25.4 \times 13.4 \mu \mathrm{m}$, $n=80$ ), L/W 1.5 to 2.9 (average $=1.9, n=80$ ).

Neofusicoccum parvum (Pennycook \& Samuels) Crous, Slippers \& A. J. L. Phillips, Stud. Mycol. 55:248. 2006 (Fig. 1 I-L).
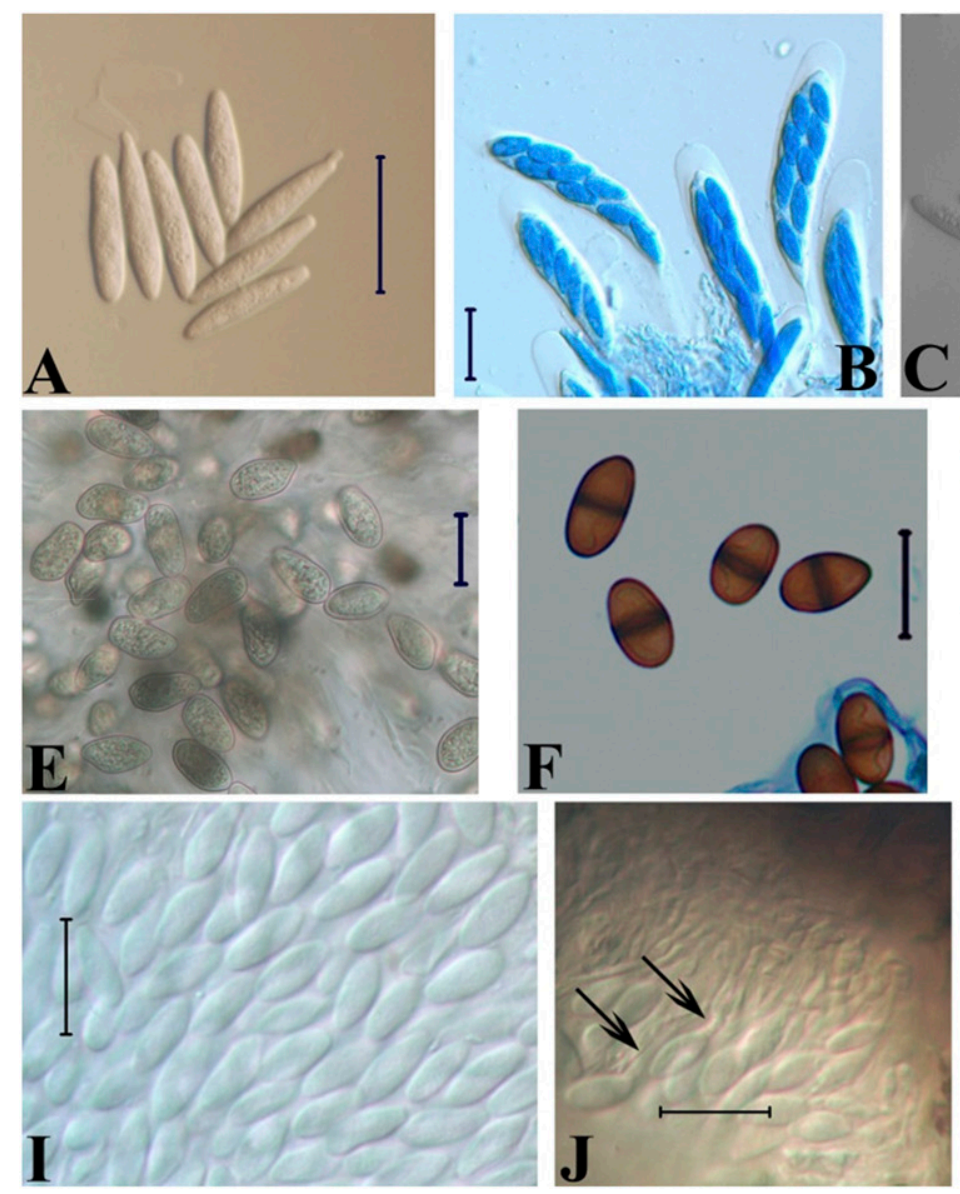
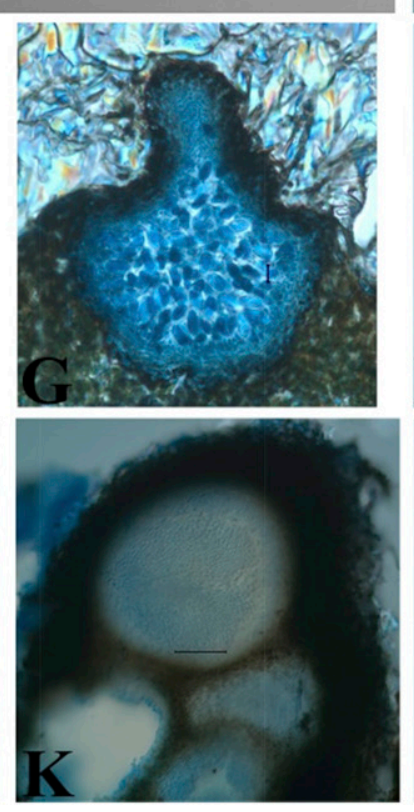
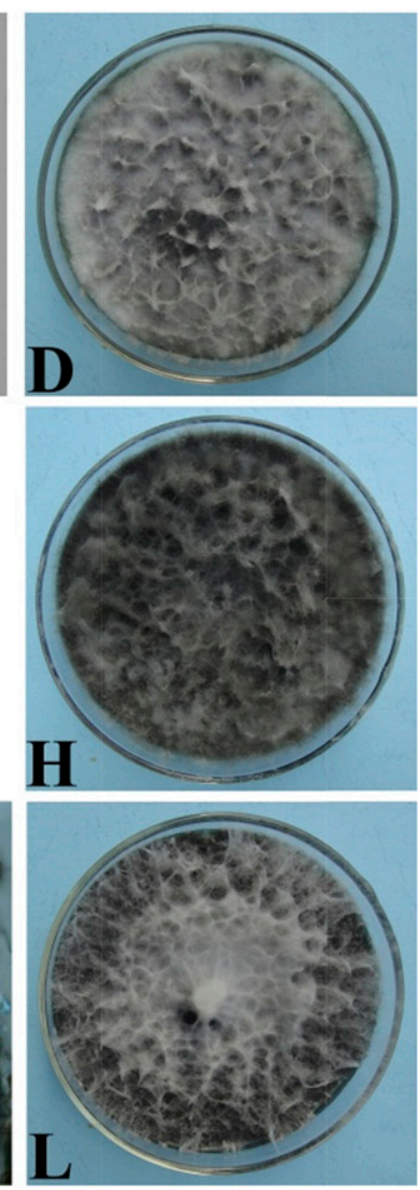

Fig. 1. Morphological characteristics of three pathogens species in the Botryosphaeriaceae family. Botryosphaeria dothidea: A, conidia from overwintered pycnidium and B, asci with ascospores from overwintered pseudothecium); B. dothidea (Mht-18): C, conidia and D, colony morphology on potato dextrose agar (PDA); Lasiodiplodia theobromae (Mht-5): E, aseptate conidia; F, 1-septate brown conidia; G, vertical section through an unilocular pycnidium; and H, colony morphology on PDA; Neofusicoccum parvum (Mht-17): I, conidia; $\mathrm{J}$, conidia developing from conidiogenous cells; $K$, vertical section through a multilocular pycnidium; and $\mathbf{L}$, colony morphology on PDA. Scale bars: $A, B, C, E, F$, and $G=25 \mu m$; $\mathrm{I}$ and $\mathrm{J}=20 \mu \mathrm{m} ; \mathrm{K}=100 \mu \mathrm{m}$. 
The colonies on PDA grew rapidly, covering the entire petri dish after approximately 5 days. Pycnidia were produced on PDA after approximately 15 days, brown to black, globose, erumpent, scattered, or clustered in small groups, multilocular. Pycnidia wall composed of textura angularis, outer parts of dark-brown cells, inner region of hyaline cells. Conidia 9.5 to $18.9 \times 3.6$ to $7.9 \mu \mathrm{m}$ (average $=14.5 \times 5.9 \mu \mathrm{m}, n=80$ ), $\mathrm{L} / \mathrm{W} 1.8$ to 3.5 (average $=2.5, n=80$ ), fusiform to ellipsoidal, at first hyaline, nonseptate, old conidia pale brown and with 1 to 2 septa.

Phylogenetic analysis. Phylogeny based on the ITS region. A maximum-parsimony tree was constructed using the ITS region of 17 isolates and 36 reference taxa (including an outgroup) (Fig. 2). Of the 454 characteristics used in the analysis, 293 were conserved and 91 were parsimony informative. A consensus tree is shown in

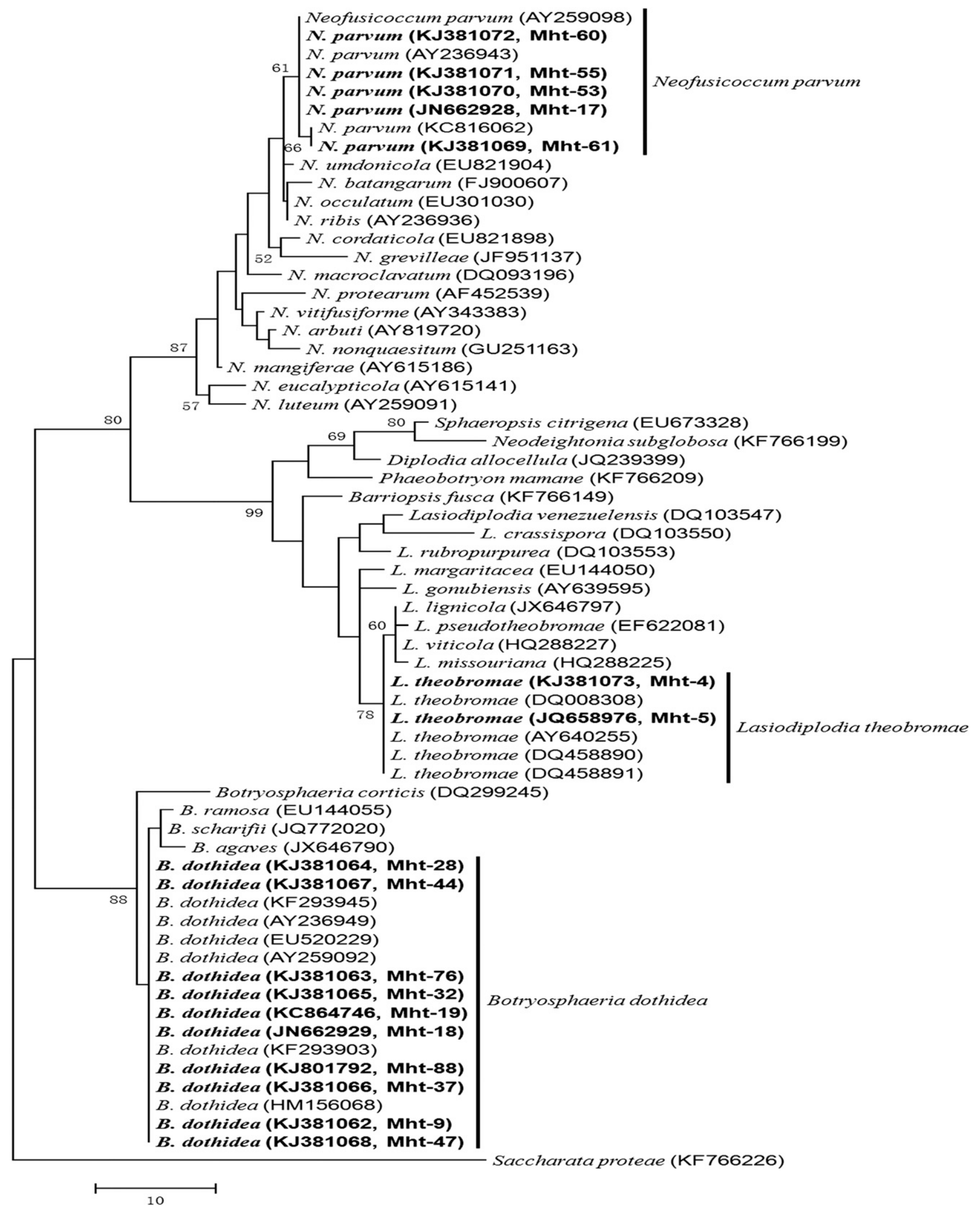

Fig. 2. Consensus maximum-parsimony tree based on the internal transcribed spacer sequence. Numbers on the branching points are $\geq 50 \%$ bootstrap values of a bootstrap test of 1,000 replicates. Isolates obtained in this study are indicated in bold. The scale bar shows 10 changes. 
Figure $2(\mathrm{TL}=189$ steps, $\mathrm{CI}=0.656, \mathrm{RI}=0.920$, and $\mathrm{RCI}=0.603)$. In the tree, the 17 isolates obtained in this study are clustered into three separate clades corresponding to $B$. dothidea, $L$. theobromae, and $N$. parvum. The submission number of the sequence alignment in TreeBASE is 16114.

Phylogeny based on combined ITS + TEF + BT sequences. A maximum-parsimony tree was constructed using the combined sequences of ITS, TEF, and BT, comprising 1,254 characteristics, of which 603 were consistent and 352 parsimony informative. The tree contained five isolates from this study and 28 reference taxa, including an outgroup (Saccharata proteae), and the consensus tree is shown in Figure $3(\mathrm{TL}=866$ steps, $\mathrm{CI}=0.629, \mathrm{RI}=0.852$, and $\mathrm{RCI}=$ 0.536). Similar to the ITS tree, three Botryosphaeriaceae species of this study are clearly separated in this tree (Fig. 3) and clustered into three separate clades: B. dothidea, L. theobromae, and N. parvum. The phylogenetic analyses confirmed the three species identified based on morphological characteristics. The submission number of the sequence alignment in TreeBASE is 16114.

Pathogenicity tests of isolates from rotten fruit. Pathogenicity on fruit and leaves of kiwifruit. Typical disease symptoms appeared on all wounded and unwounded fruit when inoculated with mycelial plugs or conidial suspensions of the isolates from rotten fruit (Fig. $4 \mathrm{~A}-\mathrm{C}, \mathrm{F}-\mathrm{H}, \mathrm{K}-\mathrm{N}$; Table 1). The symptoms were not different on fruit when inoculated with mycelial plugs or conidial suspensions of the different Botryosphaeriaceae species. In the wounded fruit test, a small brown spot appeared after inoculation with mycelial plugs for 2 days, and a clear watery and dark green ring around the inoculation site appeared later. These symptoms were also produced on wounded fruit inoculated with conidial suspensions but the progression of disease was delayed by approximately 1 day compared with that of the wounded fruit inoculated with mycelial plugs. In the unwounded fruit test, the disease symptoms were the same as for the wounded fruit but

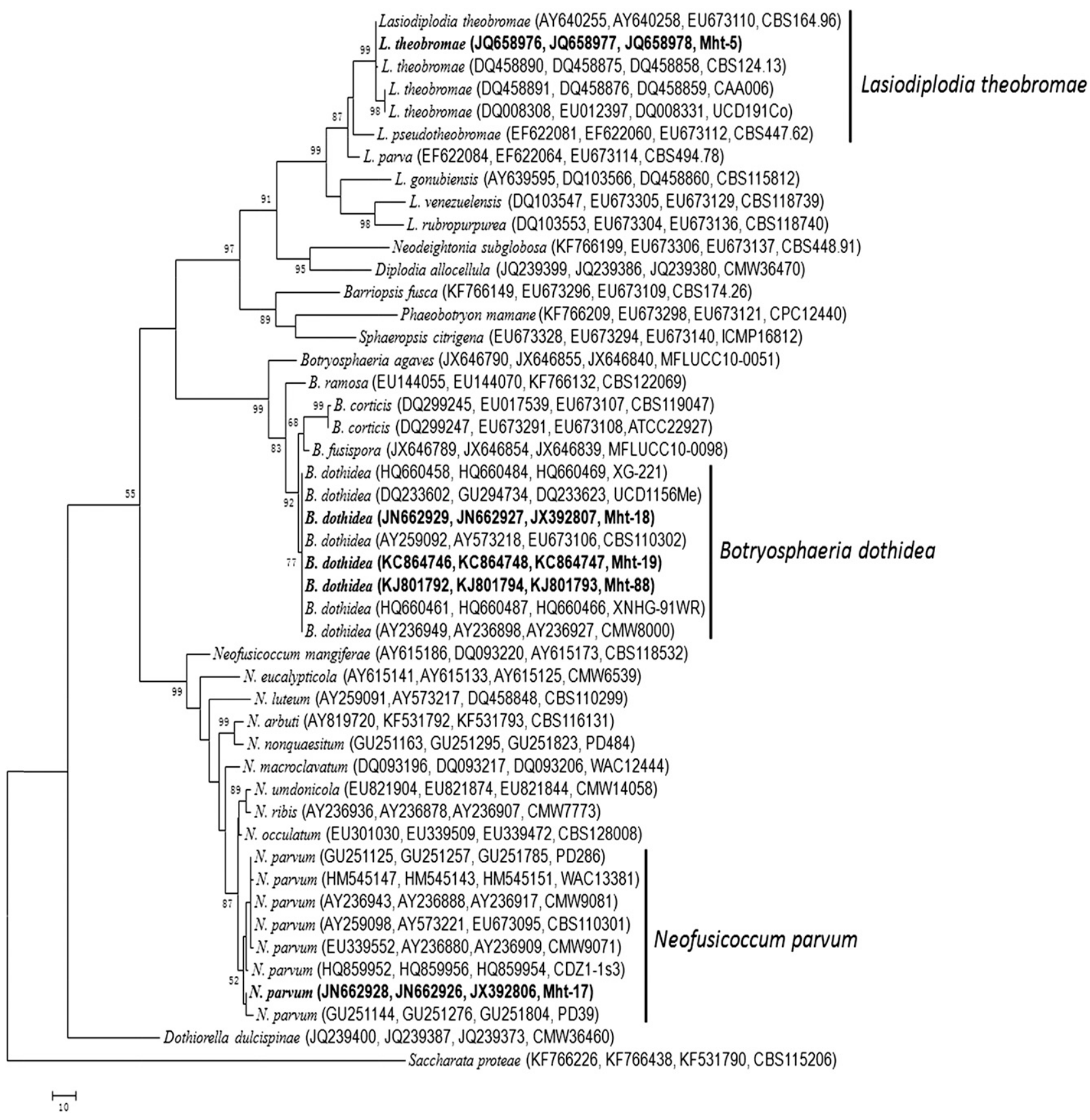

Fig. 3. Consensus maximum-parsimony tree based on a combined dataset of internal transcribed spacer (ITS), transcription elongation factor 1- $\alpha$ (TEF), and $\beta$-tubulin (BT) sequences. Bootstrap values $(\geq 50 \%$ ) of a bootstrap test of 1,000 replicates are shown on branching points. The GenBank accession number and isolate numbers (ITS, TEF, $\mathrm{BT}$, and isolate) are noted after the species names. Isolates obtained in this study are indicated in bold. The scale bar shows 10 changes. 
the progression of the disease was slower than that in the wounded fruit test. When unwounded fruit were inoculated with conidial suspensions, symptoms were produced after 3 to 4 days. Frequently, abundant mycelia appeared on wounded and unwounded fruit surfaces after the disease symptoms had been present for 4 to 7 days. When obvious symptoms were observed, the lesions expanded quickly, and the entire fruit decayed in approximately 8 days. However, L. theobromae destroyed fruit in only 5 to 6 days. The lesion symptoms were also quickly produced on the two kiwifruit cultivars (Hort and Miliang) and apple and pear fruit in approximately 2 to 4 days after inoculation with mycelial plugs, and the sunken lesion symptoms were frequently observed at the inoculation point on the Hort fruit (Fig. 4P-S).

When wounded leaves were inoculated with mycelial plugs, chlorotic to brown spots were observed after approximately 2 days (Fig. $5 \mathrm{E}-\mathrm{G})$; the same symptoms appeared on wounded leaves approximately 3 days after inoculation with conidia. Symptoms appeared after approximately 3 days when mycelial plugs were inoculated on unwounded leaves (Fig. 5C and D) and within 3 to 5 days after inoculation with conidia (Fig. $5 \mathrm{~A}$ and $\mathrm{B}$ ). The symptoms were not obviously different among the wounded and unwounded leaves by inoculation with mycelial plugs and conidia. Similar to the experiments on fruit, symptoms quickly appeared on wounded leaves after inoculation with mycelial plugs. Moreover, a large number of pycnidia formed on leaves surface about 15 to 20 days after inoculation with mycelial plugs or conidia (Fig. 5Q and R).

There were no disease symptoms on any of the controls for each of the treatments. Additionally, pathogens were recovered from the diseased fruit and leaves but not from any of the controls.

Pathogenicity on wounded shoots. The shoots with wounds made with a cork borer, inoculated with mycelial plugs of $B$. dothidea, L. theobromae, and $N$. parvum, developed dark-brown lesion within 8 to 12 days. The lesion was observed after the superficial bark was
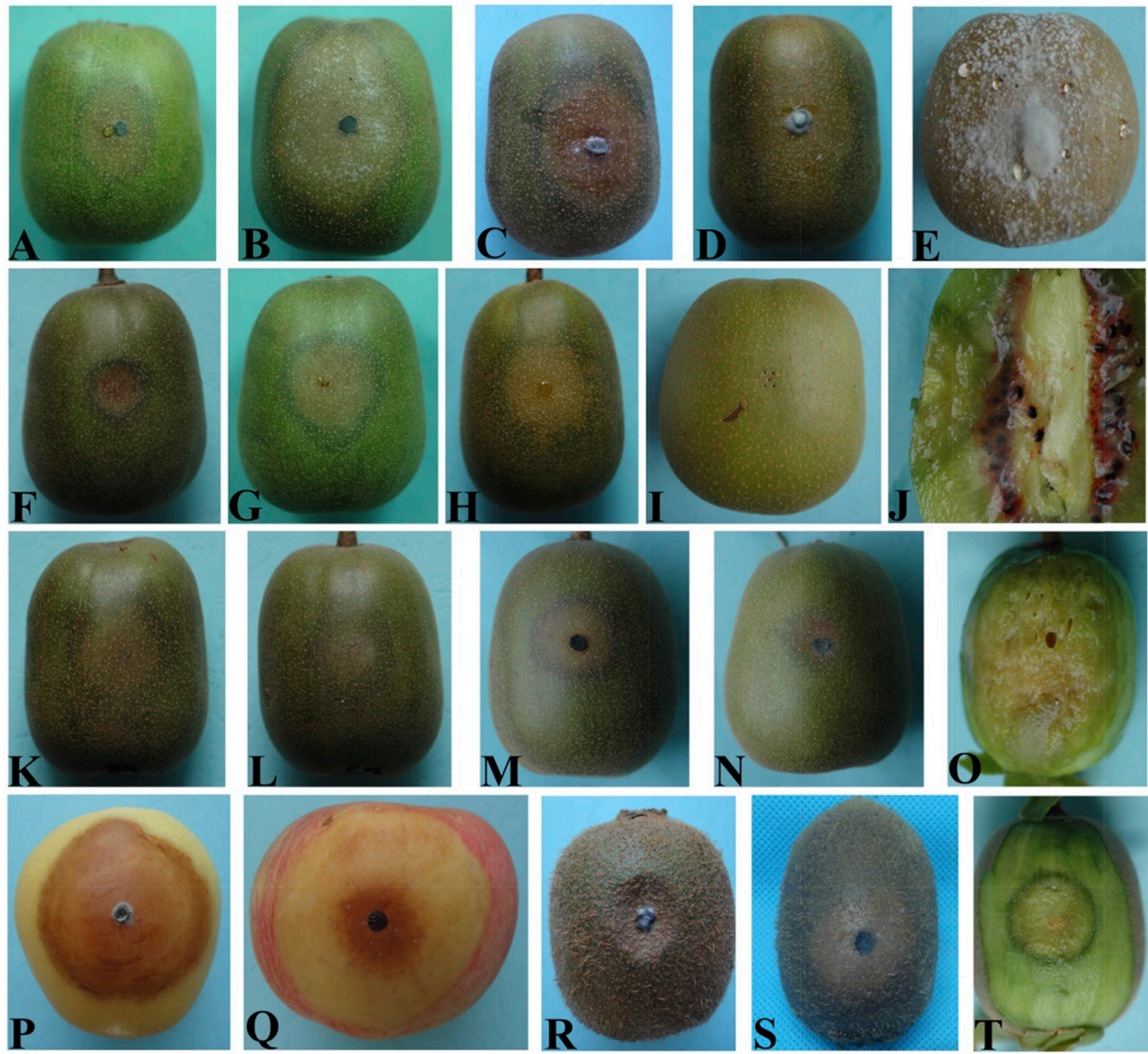

Fig. 4. Symptoms of rot on kiwifruit, apple and pear after inoculation with Botryosphaeria dothidea, Lasiodiplodia theobromae, and Neofusicoccum parvum. Symptoms on wounded fruit after inoculation with mycelial plugs of A, N. parvum (Mht-17); B, L. theobromae (Mht-5); C, B. dothidea (Mht-18); D, B. dothidea (Mht-76); and E, B. dothidea (Mht-88) Symptoms of rot on wounded fruit inoculated with conidial suspensions of F, N. parvum (Mht-17) and G, L. theobromae (Mht-5). H, Symptoms of rot on wounded fruit inoculated with an ascospore suspension from overwintered pseudothecia of $B$. dothidea (AS2). I, Control. Symptoms of rot on unwounded fruit inoculated with conidial suspensions of K, L. theobromae (Mht-5) and L, B. dothidea (Mht-18). Symptoms on unwounded fruit after inoculation with mycelial plugs of $\mathbf{M}, \mathbf{L}$. theobromae (Mht-5) and N, B. dothidea (Mht-19). Symptoms of rot on P, pear; Q, apple; R, Hort kiwifruit; and S, Miliang kiwifruit after inoculation with mycelial plugs of N. parvum (Mht-17). J, 0, and T, Symptoms of internal rot on fruit after inoculation with mycelial plugs from $B$. dothidea (Mht-18). 
removed from the shoots. These lesions extended both upward and downward from the inoculation site (Fig. 5I-K). The dark-brown lesions also developed on shoots after inoculation with conidia. On the needle-pricked wound shoots, lesions symptoms were also induced within approximately 10 days by these three Botryosphaeriaceae species after inoculation using mycelial plugs or conidia (Fig. $5 \mathrm{~L})$. As the infection progressed, a large number of pycnidia developed on the shoot surface (Fig. 5U).

When L. theobromae (Mht-5) was inoculated on twigs in the orchards, the brown lesion symptoms were dull and elliptical (Fig. $5 \mathrm{~N}$ ), and the dark-brown lesions extended across the bark of the twigs after approximately 18 days; the twigs eventually became blighted. Sunken lesions formed on the wounded shoots after approximately 15 days (Fig. 5O), and L. theobromae (Mht-5) occasionally caused a split of the periderm at the point of inoculation (Fig. 5P). However, pycnidia were not observed on the surface of the twigs and shoots, even after 30 days.

There were no disease symptoms on any of the controls of these treatments, and the pathogens were successfully reisolated from symptomatic tissues but not from healthy controls.

The pathogenicity of overwintered conidia and ascospores. In April 2012, a large number of fruiting bodies (pycnidia and pseudothecia) of B. dothidea were observed. In August 2012, pycnidia and pseudothecia of $B$. dothidea were also observed but the number of pseudothecia exceeded pycnidia, and some of these structures were empty. Pycnidia and pseudothecia were embedded in black stromata alone or arranged in groups, and they were macroscopic when the stromata broke up the superficial bark of the dead wood (Fig. 5S and T).

According to morphological characterization, the conidial and ascospore suspensions obtained from the pycnidia and pseudothecia in April and August 2012 were grouped into one morphotype and identified as B. dothidea (Fig. 1A and B). Four selected representative single-spore cultured isolates (Mht-19, Mht-32, Mht-76, and Mht88 ) from the collected conidial and ascospore suspensions were all identified as $B$. dothidea according to morphological and molecular characteristics.

When inoculated with conidial or ascospore suspensions of $B$. dothidea obtained from the overwintered pycnidia and pseudothecia, typical disease symptoms appeared on all fruit and leaves of kiwifruit (wounded and unwounded; Fig. 4H; Table 1). At approximately 18 days after inoculation with either a conidial or ascospore suspension, a large number of pycnidia began to form on the surface of leaves. The mycelial plugs and conidia of isolates Mht-19, Mht-32,

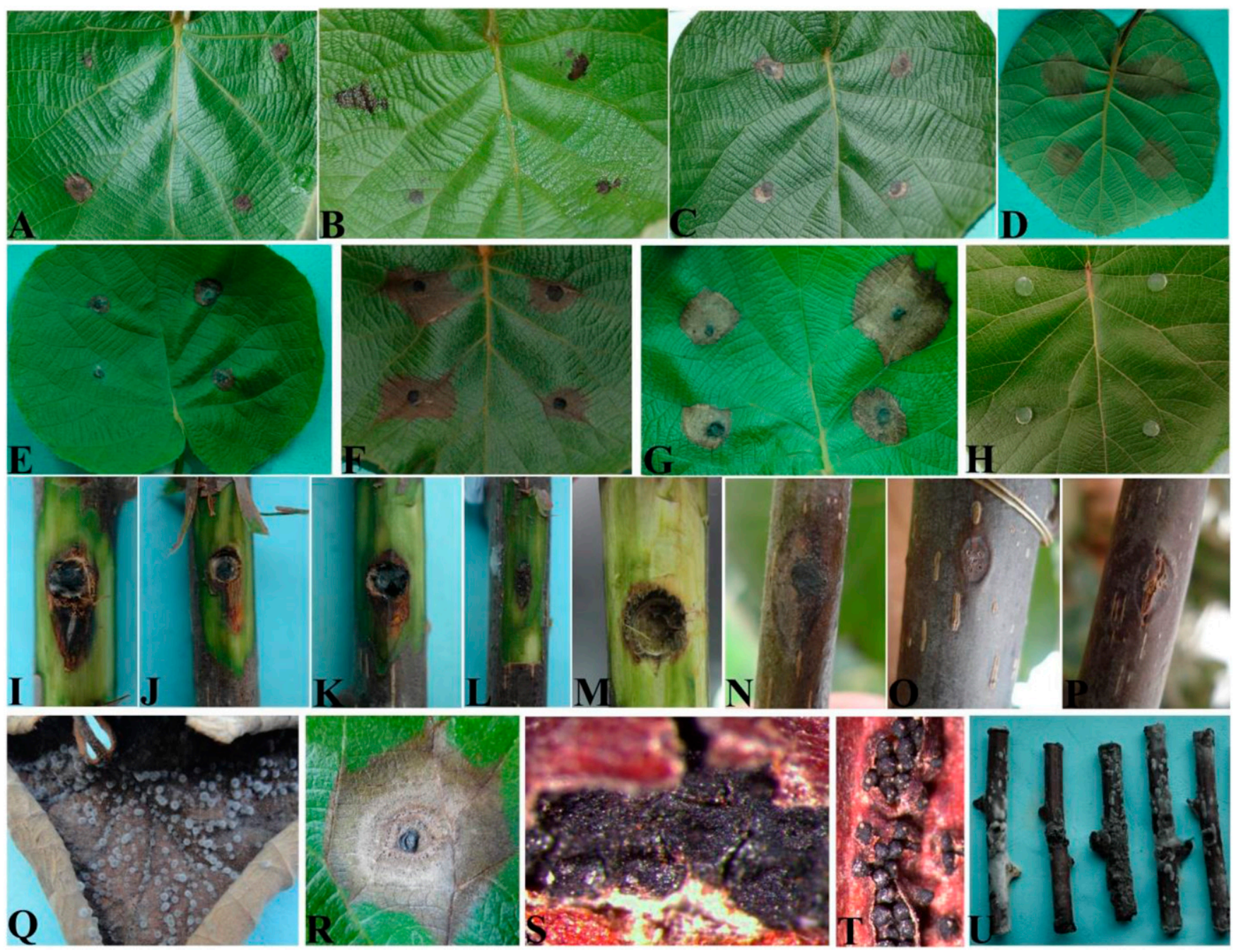

Fig. 5. Disease symptoms on leaves and shoots after inoculation with Botryosphaeria dothidea, Lasiodiplodia theobromae, and Neofusicoccum parvum and the fruiting bodies of these pathogens on leaves and shoots. Spots appeared on unwounded leaves after inoculation with conidial suspensions of A, N. parvum (Mht-17) and B, L. theobromae (Mht-5). Spots appeared on unwounded leaves after inoculation with mycelial plugs of $\mathbf{C}$ and $\mathbf{D}, B$. dothidea (Mht-18) (C positive and $D$ reverse). Spots appeared on wounded leaves after inoculation with mycelial plugs of E, B. dothidea (Mht-18); F, N. parvum (Mht-17); and G, L. theobromae (Mht-5). H, Control. Lesions on rounded wounded 1-year-old shoots after inoculation with mycelial plugs of I, B. dothidea (Mht-18); J, N. parvum (Mht-17); and K, L. theobromae (Mht-5). L, Lesions on needle-pricked wounded 1-year-old shoots after inoculation with conidial suspensions of N. parvum (Mht-17). M, Control. N-P, Lesions on twig and needle-pricked wounded 1-year-old shoots after inoculation with mycelial plugs of L. theobromae (Mht-5) in the orchard. Pycnidia of Q, B. dothidea (Mht-18) and R, L. theobromae (Mht-5) produced on the leaves surface. S, Pycnidia of B. dothidea on the shoot. T, Pseudothecia of $B$. dothidea on the shoot. U, Pycnidia of B. dothidea, L. theobromae, and N. parvum were produced on the surface of shoots. 
Mht-76, and Mht-88 could also cause disease symptoms on fruit and leaves of kiwifruit (wounded and unwounded) (Fig. 4D, E, and N; Table 1).

The pathogens were reisolated from the diseased tissues of the inoculated fruit and leaves but not from the controls.

\section{Discussion}

Diagnosis of the pathogens of kiwifruit rot is the key for successful control of this disease. According to morphological characteristics, phylogenetic analysis, and pathogenicity testing, this study shows that $B$. dothidea, $L$. theobromae, and $N$. parvum are the causal agents of this disease.

These three Botryosphaeriaceae species are able to cause lesions on fruit, leaves, and shoots of Hongyang kiwifruit and also can cause rot symptoms on fruit of other two kiwifruit cultivars (Hort and Miliang), apple, and pear. The results indicate that the host of these pathogens is not limited to kiwifruit. Based on pathogenicity tests on fruit and leaves, $L$. theobromae causes lesion symptoms more quickly than both $B$. dothidea and $N$. parvum. The pathogenicity testing also showed that disease symptoms occurred quickly on wounded fruit and leaves, faster than on unwounded fruit and leaves. Previous studies reported that some pathogens in the Botryosphaeriaceae family can directly infect healthy fruit and leaves through natural openings $(13,19,24,25,41)$. Our study revealed that the presence of a wound is not necessary for pathogens to infect the fruit and leaves of kiwifruit but wounding can enhance the severity of symptoms.

In a previous study, D. mutila (syn. $B$. stevensii), which can cause kiwifruit rot, was also isolated from kiwifruit leaves (11). In addition, $B$. dothidea and $N$. parvum were reported to cause shoot blight of kiwifruit $(37,51)$. In our other study (unpublished data), B. dothidea and $N$. parvum were isolated most commonly from irregularly shaped spots on kiwifruit leaves. This research indicated that kiwifruit leaves and shoots may have an important role in the infection cycle of kiwifruit rot. According to the report by Thomidis et al. (52), N. parvum could overwinter as pycnidia on blighted shoots and the diseased plant debris of peach trees from the previous year. Conidia of $N$. parvum from the overwintered pycnidia were the primary inoculum sources of the present year, and new pycnidia could serve as a secondary inoculum source. We found numerous pycnidia and pseudothecia of $B$. dothidea on kiwifruit dead wood in orchards in April and August of 2012, and the pathogenicity tests of the conidia and ascospores obtained from these pycnidia and pseudothecia showed that both can cause kiwifruit rot and necrotic spots on leaves. Thus, the pycnidia and pseudothecia of $B$. dothidea are able to overwinter in orchards and produce conidia and ascospores as inoculum sources for fruit and leaves in the following year. Moreover, in our inoculation experiments, a large number of pycnidia commonly developed on leaves and shoots after inoculation with $B$. dothidea, $L$. theobromae, and $N$. parvum. Therefore, we speculated that the Botryosphaeriaceae pathogens can form fruiting bodies on kiwifruit orchard and overwintering, and the overwintered fruiting bodies should be the main primary inoculum sources for kiwifruit rot.

Based on our results, we suspect that there are two ways by which $B$. dothidea infects the fruit after overwintering. First, in the spring or early summer, pycnidia or pseudothecia release spores to infect leaves and shoots or may infect buds. Then, new pycnidia develop during the growing season and release conidia as a secondary inoculum source, eventually infecting fruit. Second, pycnidia or pseudothecia survive until fruit set and then release conidia or ascospores to directly infect fruit. Both routes possibly exist in the kiwifruit rot disease cycle. We did not find pycnidia or pseudothecia of $L$. theobromae and N. parvum on dead wood, fallen leaves, other diseased plant residues, or other living parts of kiwifruit trees, and their fruiting bodies were similarly not found on other types of plants (such as Camellia japonica and Osmanthus fragrans) adjacent to the kiwifruit orchards. Therefore, the initial source of $L$. theobromae and $N$. parvum in these kiwifruit orchards is not clear, and further investigation is needed.

Sutton's research indicated that conidia are the primary source of inoculum in apple orchards (42). However, in peach orchards, airborne ascospores could be the major primary inoculum (36). Conidia and ascospores of $B$. dothide $a$ could be produced on the pruning material and dead bark of apple trees as a primary inoculum but more spores are generally produced on 1-year-old prunings $(42,43)$. Drake's research showed that, if the bark remains on twigs of apple, then $N$. ribis (syn. B. ribis) and Physalospora obtuse could continue producing pycnidiospores on bark for at least 6 years, serving as the inoculum source for apple fruit rot (9). Therefore, we inferred that reducing the primary infection is perhaps one of the control strategies for kiwifruit rot.

To our knowledge, this is the first report of $L$. theobromae and $N$. parvum causing kiwifruit rot in China. This study also reports that $B$. dothidea can form pycnidia and pseudothecia as overwintering structures in kiwifruit orchards, serving as the primary inoculum source for kiwifruit rot.

\section{Acknowledgments}

This study was funded by a project from Sichuan Province (2013JY0115 and 2014NZ0104). We thank X. Chen at Washington State University for helping to modify the manuscript; and J. Wang, S. He, M. Ye, G. Tang, and D. Peng at Sichuan Agricultural University for supporting the investigation and research work

\section{Literature Cited}

1. Alves, A., Crous, P. W., Correia, A., and Phillips, A. J. L. 2008 Morphological and molecular data reveal cryptic speciation in Lasiodiplodia theobromae. Fungal Divers. 28:1-13.

2. Barber, P. A., Burgess, T. J., Hardy, G. E., Slippers, B., Keane, P. J., and Wingfield, M. J. 2005. Botryosphaeria species from Eucalyptus in Australia are pleoanamorphic, producing Dichomera synanamorphs in culture. Mycol. Res. 109:1347-1363.

3. Barnes, I., Roux, J., Coetzee, M. P. A., and Wingfield, M. J. 2001. Characterization of Seiridium spp. associated with cypress canker based on $\beta$-tubulin and histone sequences. Plant Dis. 85:317-321.

4. Burgess, T. I., Barber, P. A., Mohali, S., Pegg, G., Beer, W. D., and Wingfield, M. J. 2006. Three new Lasiodiplodia spp. from the tropics, recognized based on DNA sequence comparisons and morphology. Mycologia 98:423-435.

5. Cardoso, M., Diniz, I., Cabral, A., Rego, C., and Oliveira, H. 2013. Unveiling inoculum sources of black foot pathogens in a commercial grapevine nursery. Phytopathol. Mediterr. 52:298-312.

6. Crous, P. W., Slippers, B., Wingfield, M. J., Rheeder, J., Marasas, W. F. O. Philips, A. J. L., Alves, A., Burgess, T., Barber, P., and Groenewald, J. Z 2006. Phylogenetic lineages in the Botryosphaeriaceae. Stud. Mycol. 55:235-253.

7. Denman, S., Crous, P. W., Taylor, J. E., Kang, J. C., Pascoe, I., and Wingfield, M. J. 2000. An overview of taxonomic history of Botryosphaeria, and a reevaluation of its anamorphs based on morphology and ITS rDNA phylogeny. Stud. Mycol. 45:129-140.

8. de Oliveira Costa, V. S., Michereff, S. J., Martins, R. B., Gava, C. A. T., Mizubuti, E. S. G., and Câmara, M. P. S. 2010. Species of Botryosphaeriaceae associated on mango in Brazil. Eur. J. Plant Pathol. 127:509-519.

9. Drake, C. R. 1971. Sources and longevity of apple fruit rot in inoculum, Botryosphaeria ribis and Physalospora obtusa, under orchard conditions. Plant Dis. Rep. 55:122-126.

10. Guo, L. D., Hyde, K. D., and Liew, E. C. Y. 1998. A method to promote sporulation in palm endophytic fungi. Fungal Divers. 1:109-113.

11. Hawthorne, B. T., Rees-George, J., and Samuels, G. J. 1982. Fungi associated with leaf spots and post-harvest fruit rots of kiwifruit (Actinidia chinensis) in New Zealand. N.Z. J. Bot. 20:143-150.

12. Hawthorne, B. T., and Reid, M. S. 1982. Possibility for fungicidal control of kiwifruit fungal storage rots. N. Z. J. Exp. Agric. 10:333-336.

13. Kim, K. W., Park, E. W., and Ahn, K. K. 1999. Pre-penetration behavior of Botryosphaeria dothidea on apple fruits. Plant Pathol. J. 15:223-227.

14. Kinugawa, M., and Sato, T. 2003. Kiwifruit dieback caused by Diaporthe sp. and Botryosphaeria dothidea, kiwifruit soft rot fungi. Jpn. J. Phytopathol. 69: 373-383.

15. Kirk, P. M., Cannon, P. F., David, J. C., and Stalpers, J. A. 2001. Dictionary of the Fungi, 9th ed. CAB International, Wallingford, U.K.

16. Koh, Y. J., Hur, J. S., and Jung, J. S. 2005. Postharvest fruit rots of kiwifruit (Actinidia deliciosa) in Korea. N. Z. J. Crop Hortic. 33:303-310.

17. Lazzizera, C., Frisullo, S., Alves, A., and Phillips, A. J. L. 2008. Morphology, phylogeny and pathogenicity of Botryosphaeria and Neofusicoccum species associated with drupe rot of olives in southern Italy. Plant Pathol. 57:948-956.

18. Li, C., Jiang, J. X., Leng, J. H., Li, B. M., Yu, Q., and Tu, G. Q. 2012. Isolation and identification of pathogenic fungi causing fruit rot of kiwifruit in Fengxin County. Acta Agric. Univ. Jiangxiensis (Nat. Sci. Edn.) 34:259-263. (In Chinese)

19. Li, G. X., Shen, Y. B., Gao, Y. M., Chen, J., and Jie, Y. U. 2006. Infection process of Botryosphaeria dothidea in apple fruit. J. Fruit Sci. 23:69-72. (In Chinese)

20. Luongo, L., Santori, A., Riccioni, L., and Belisario, A. 2011. Phomopsis sp. associated with post-harvest fruit rot of kiwifruit in Italy. J. Plant Pathol. 93 205-209. 
21. Lynch, S. C., Eskalen, A., Zambino, P. J., Mayorquin, J. S., and Wang, D. H. 2013. Identification and pathogenicity of Botryosphaeriaceae species associated with coast live oak (Quercus agrifolia) decline in southern California. Mycologia 105:125-140.

22. Manning, M. A., Meier, X., Olsen, T. L., and Johnston, P. R. 2003. Fungi associated with fruit rots of Actinidia chinensis 'Hort16A' in New Zealand. N. Z. J. Crop Hortic. 31:315-324

23. Marincowitz, S., Groenewald, J. Z., Wingfield, M. J., and Crous, P. W. 2008. Species of Botryosphaeriaceae occurring on Proteaceae. Persoonia 21:111-118.

24. Michailides, T. J. 1991. Pathogenicity, distribution, sources of inoculums, and infection courts of Botryosphaeria dothidea on pistachio. Phytopathology 81: 566-573.

25. Moral, J., Muñoz-Díez, C., González, N., Trapero, A., and Michailides, T. J. 2010. Characterization and pathogenicity of Botryosphaeriaceae species collected from olive and other hosts in Spain and California. Phytopathology 100:1340-1351.

26. Opgenorth, D. C. 1983. Storage rot of California-grown Kiwifruit. Plant Dis. 67:382-383.

27. Pavlic, D., Slippers, B., Coutinho, T. A., and Wingfield, M. J. 2009. Multiple gene genealogies and phenotypic data reveal cryptic species of the Botryosphaeriaceae: A case study on the Neofusicoccum parvum/N. ribis complex. Mol. Phylogenet. Evol. 51:259-268.

28. Pennycook, S. R. 1985. Fungal fruit rots of Actinidia deliciosa (kiwifruit). N. Z. J. Exp. Agric. 13:289-299.

29. Pérez, C. A., Wingfield, M. J., Slippers, B., Altier, N. A., and Blanchette, R. A. 2010. Endophytic and canker-associated Botryosphaeriaceae occurring on non-native Eucalyptus and native Myrtaceae trees in Uruguay. Fungal Divers. 41:53-69.

30. Petrak, F. 1923. Mycologische Notizen V. No. 200. Über die Pseudosphaeriaceen v.H und ihre Bedeutung für die spezielle Systematik der Pyrenomyzeten. Ann. Mycol. 21:30-69.

31. Phillips, A. J. L. 2002. Botryosphaeria species associated with diseases of grapevines in Portugal. Phytopathol. Mediterr. 41:3-18.

32. Phillips, A. J. L., Alves, A., Abdollahzadeh, J., Slippers, B., Wingfield, M. J., Groenewald, J. Z., and Crous, P. W. 2013. The Botryosphaeriaceae: Genera and species known from culture. Stud. Mycol. 76:51-167.

33. Phillips, A. J. L., Alves, A., Pennycook, S. R., Johnston, P. R., Ramaley, A., Akulov, A., and Crous, P. W. 2008. Resolving the phylogenetic and taxonomic status of dark-spored teleomorph genera in the Botryosphaeriaceae. Persoonia 21:29-55.

34. Phillips, A. J. L., Oudemans, P. V., Correia, A., and Alves, A. 2006. Characterisation and epitypification of Botryosphaeria corticis, the cause of blueberry cane canker. Fungal Divers. 21:141-155.

35. Phillips, A. J. L., Rumbos, I. C., Alves, A., and Correia, A. 2005. Morphology and phylogeny of Botryosphaeria dothidea causing fruit rot of olives. Mycopathologia 159:433-439.

36. Pusey, P. L. 1989. Availability and dispersal of ascopores and conidia of Botryosphaeria in peach Orchards. Phytopathology 79:635-639.

37. Rumbos, I. C., and Phillips, A. J. L. 2005. A new disease of kiwifruit caused by Botryosphaeria parva. S. Afr. J. Sci. 101, 7/8:314.

38. Sivanesan, A. 1984. The Bitunicate Ascomycetes and Their Anamorphs. J. Cramer Press, Vaduz, Liechtenstein.

39. Slippers, B., Boissin, E., Phillips, A. J. L., and Groenewald, J. Z. 2013. Phylogenetic lineages in the Botryosphaeriales: A systematic and evolutionary framework. Stud. Mycol. 76:31-49.

40. Slippers, B., Johnson, G. I., Crous, P. W., Coutinho, T. A., Wingfield, B. D., and Wingfield, M. J. 2005. Phylogenetic and morphological re-evaluation of the Botryosphaeria species causing diseases of Mangifera indica. Mycologia 97:99-110.

41. Slippers, B., and Wingfield, M. J. 2007. Botryosphaeriaceae as endophytes and latent pathogens of woody plants: Diversity, ecology and impact. Fungal Biol. Rev. 21:90-106.

42. Sutton, T. B. 1981. Production and dispersal of ascospores and conidia by Physalospora obtusa and Botryosphaeria dothidea in apple orchards. Phytopathology 71:584-589.

43. Sutton, T. B., and Arauz, L. F. 1991. Influence of temperature and moisture on germination of ascospores and conidia of Botryosphaeria dothidea. Plant Dis. 75:1146-1149.

44. Tamura, K., Peterson, D., Peterson, N., and Stecher, G. 2011. MEGA5 Molecular evolutionary genetics analysis using maximum likelihood, evolutionary distance, and maximum parsimony methods. Mol. Biol. Evol. 28:2731-2739.

45. Tanaka, K., Hirayama, K., Yonezawa, H., Hatakeyama, S., Harada, Y., Sano, T., Shirouzu, T., and Hosoya, T. 2009. Molecular taxonomy of bambusicolous fungi: Tetraplosphaeriaceae, a new pleosporalean family with Tetraploa-like anamorphs. Stud. Mycol. 64:175-209.

46. Tang, W., Ding, Z., Zhou, Z. Q., Wang, Y. Z., and Guo, L. Y. 2012. Phylogenetic and pathogenic analyses show that the causal agent of apple ring rot in China is Botryosphaeria dothidea. Plant Dis. 96:486-496.

47. Taylor, K., Barber, P. A., Hardy, G. E., and Burgess, T. I. 2009 Botryosphaeriaceae from tuart (Eucalyptus gomphocephala) woodland, including descriptions of four new species. Mycol. Res. 113:337-353.

48. Taylor, A., Hardy, G. E., Wood, P., and Burgess, T. 2005. Identification and pathogenicity of Botryosphaeria species associated with grapevine decline in Western Australia. Australas. Plant Pathol. 34:187-195.

49. Theissen, F., and Sydow, H. 1915. Die Dothideales. Ann. Mycol. 13:149-746

50. Theissen, F., and Sydow, H. 1918. Vorentwürfe zu den Pseudosphaeriales. Ann. Mycol. 16:1-34.

51. Thomidis, T., and Exadaktylou, E. 2010. First report of Botryosphaeria dothidea causing shoot blight of kiwifruit (Actinidia deliciosa) in Greece. Plant Dis. 94:1503.

52. Thomidis, T., Michailides, T. J., and Exadaktylou, E. 2011. Neofusicoccum parvum associated with fruit rot and shoot blight of peaches in Greece. Eur. J. Plant Pathol. 131:661-668

53. van Niekerk, J. M., Crous, P. W., Groenewald, J. Z., Fourie, P. H., and Halleen, F. 2004. DNA phylogeny, morphology and pathogenicity of Botryosphaeria species on grapevines. Mycologia 96:781-798.

54. von Arx, J. A., and Müller, E. 1975. A re-evaluation of the bitunicate Ascomycetes with keys to families and genera. Stud. Mycol. 9:1-159.

55. Wang, F., Zhao, L., Li, G., Huang, J., and Hsiang, T. 2011. Identification and characterization of Botryosphaeria spp. causing gummosis of peach trees in Hubei Province, central China. Plant Dis. 95:1378-1384.

56. Wang, H. K., Aptroot, A., Crous, P. W., Hyde, K. D., and Jeewon, R. 2007. The polyphyletic nature of Pleosporales: An example from Massariosphaeria based on rDNA and RBP2 gene phylogenies. Mycol. Res. 111:1268-1276.

57. White, T. J., Bruns, T., Lee, S., and Taylor, J. 1990. Amplification and direct sequencing of fungal ribosomal RNA genes for phylogenies. Pages 315-322 in: PCR Protocols: A Guide to Methods and Applications. M. A. Innis, D. H. Gelfand, J. J. Sninsky, and T. J. White, eds. Academic Press, New York.

58. Yan, J. Y., Cui, Y. L., Ding, J., Zhou, L. Q., Chen, Z. Q., and Zhang, M. 2013. Isolation and identification of the causal pathogens for kiwifruit bacterial canker and the isolation of the antagonistic endophytic fungi from kiwifruit in Sichuan, China. J. Agric. Sci. 5:262-268. 